\title{
Deoxytrifluoromethylthiolation and Selenylation of Alcohols using Benzothiazolium Reagents
}

\author{
Stefan Dix, ${ }^{[a]}$ Michael Jakob ${ }^{[a]}$ and Matthew N. Hopkinson*[a]
}

\begin{abstract}
Aliphatic compounds substituted with medicinally-important trifluoromethylthio $\left(\mathrm{SCF}_{3}\right)$ and trifluoromethylselenyl $\left(\mathrm{SeCF}_{3}\right)$ groups have been synthesized directly from alcohols using the new benzothiazolium salts $\mathbf{B T}-\mathbf{S C F}_{3}$ and $\mathbf{B T}-\mathbf{S e C F}_{3}$. These bench-stable fluorine-containing reagents are facile to use and can be prepared in two steps from non-fluorinated heteroaromatic starting materials. The metal-free deoxytrifluoromethylthiolation process using $\mathbf{B T}_{-} \mathbf{S C F}_{3}$ proceeds under mild conditions while the similarly efficient trifluoromethylselenylation reactions using $\mathbf{B T}-\mathbf{S e C F}_{3}$ are, to the best of our knowledge, the first reported examples of this transformation.
\end{abstract}

Substituting organic molecules with fluorine is a common strategy to improve their biological or physical properties. ${ }^{[1]}$ In addition to single fluorine atoms and established fluorinated moieties such as the trifluoromethyl group $\left(\mathrm{CF}_{3}\right)$, alternative fluorine-containing functional groups have been attracting increasing attention. With the highest reported Hansch parameter $(\pi=1.44)$ and strong electron-withdrawing properties (Hammett parameters: $\sigma_{\mathrm{m}}=0.40$, $\left.\sigma_{\mathrm{p}}=0.50\right)$, the trifluoromethylthio $\left(\mathrm{SCF}_{3}\right)$ group in particular has emerged as a promising substituent in pharmaceuticals that counterintuitively combines significant polarity with high lipophilicity. [2]

The resurgence in interest in the $\mathrm{SCF}_{3}$ group has been driven in large part by the introduction of new reagents for electrophilic trifluoromethylthiolation. As demonstrated in a number of impressive contributions, reagents such as $N$ (trifluoromethylthio)phthalimide, ((2) (2-iodophenyl)propan-2yl)oxy)(trifluoromethyl)sulfane and Billard's trifluoromethyl sulfenamides have opened up new mild synthetic routes towards $\mathrm{SCF}_{3}$-substituted molecules that were not accessible using the previously-available toxic gases $\mathrm{F}_{3} \mathrm{CS}-\mathrm{Cl}$ and $\mathrm{F}_{3} \mathrm{CS}-\mathrm{SCF}_{3} \cdot{ }^{[2,3]} \mathrm{By}$ contrast, nucleophilic trifluoromethylthiolation reactions are typically performed using only a handful of ${ }^{-} \mathrm{SCF}_{3}$ sources such as $\mathrm{AgSCF}_{3}, \mathrm{CuSCF}_{3}$ and $\left[\mathrm{Me}_{4} \mathrm{~N}_{\mathrm{SCF}} \mathrm{SC}_{3}{ }^{[2]}\right.$ In addition to their high cost, a major challenge associated with these reagents is the relative instability of the free $-\mathrm{SCF}_{3}$ anion as $\beta$-elimination of fluoride can outcompete the desired nucleophilic trifluoromethylthiolation process. ${ }^{[4]}$ An alternative strategy is to instead employ a stable organic reagent which releases ${ }^{-} \mathrm{SCF}_{3}$ upon in situ-activation. ${ }^{[5]}$ Using this approach, free ${ }^{-} \mathrm{SCF}_{3}$ anions

[a] M.Sc. S. Dix, B.Sc. M. Jakob, Jun.-Prof. M. N. Hopkinson Institute of Chemistry and Biochemistry

Freie Universität Berlin

Takustrasse 3, 14195 Berlin (Germany)

E-mail: matthew.hopkinson@fu-berlin.de

Website: https://www.bcp.fu-berlin.de/en/chemie/chemie/forschung/ OrgChem/hopkinson/index.html

Supporting information for this article is given via a link at the end of the document. a)

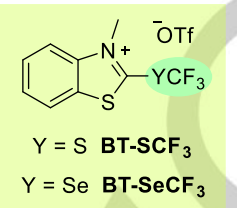

Bench-stable, easy-to-handle solids Two-step synthesis from heteroaromatics BT-SCF ${ }_{3}$ enables mild and efficient deoxytrifluoromethylthiolation of alcohols BT-SeCF ${ }_{3}$ enables unprecedented deoxytrifluoromethylselenylation of alcohols

b) Qing $^{[12]}$

$\mathrm{AgSCF}_{3}$ (3-4 equiv)

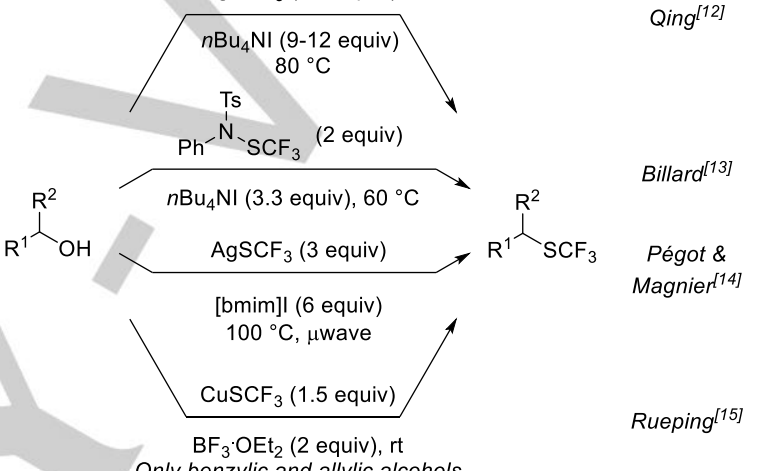
Only benzylic and allylic alcohols

$$
\text { c) This Work: }
$$

Scheme 1. a) Benzothiazolium Reagents $\mathbf{B T}-\mathbf{S C F}_{3}$ and $\mathbf{B T}-\mathbf{S e C F}_{3}$. b) Previously-reported deoxytrifluoromethylthiolation reactions of aliphatic alcohols. c) This work: Deoxytrifluoromethylthiolation and selenylation of

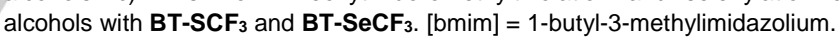

are generated in a more controlled fashion while reactive electrophiles for nucleophilic substitution reactions can be generated as part of the activation process. Inspired by the success of azolium-based reagents such as 2,2-difluoro-1,3dimethylimidazolidine (DFI) and Alkylfluor ${ }^{\circledR}$ in nucleophilic fluorination $^{[6]}$ and the use of benzothiazolium salts in coupling reactions, ${ }^{[7]}$ we considered whether the $2-\mathrm{SCF}_{3}$-substituted benzothiazolium species $\mathbf{B T}^{-\mathbf{S C F}_{3}}$ (Scheme 1a) could be employed as a new bench-stable metal-free reagent for nucleophilic trifluoromethylthiolation reactions. Herein we report the synthesis of $\mathbf{B T}-\mathbf{S C F}_{3}$ and its successful application in mild deoxytrifluoromethylthiolation reactions of aliphatic alcohols. Moreover, $\mathrm{SeCF}_{3}$-substituted alkyl derivatives could be readily prepared in an unprecedented deoxytrifluoromethylselenylation process using the analogous selenium reagent $\mathbf{B T}-\mathbf{S e C F}_{3}$.

The synthesis of BT-SCF 3 is shown in Scheme 2a. A two-step approach was investigated starting from inexpensive 2mercaptobenzothiazole (MBT), which is an industrially-produced bulk material used in the sulfur vulcanization of rubber. In the first step, trifluoromethylation of MBT affords the stable 
heteroaromatic species $\mathbf{1}$, which can be readily purified by column chromatography without decomposition. A reactive reagent is only generated in the second step with simple methylation of the

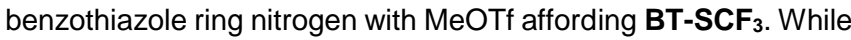
there are several literature methods for conducting the $S$ trifluoromethylation of $\mathrm{MBT},{ }^{[8]}$ we found that intermediate compound 1 could be most efficiently generated starting from the disulfide dimer MBTS via an in-house-developed photoredox catalysis method. ${ }^{[8 a, 9]}$ Blue light irradiation of inexpensive MBTS with the Langlois reagent $\left(\mathrm{NaSO}_{2} \mathrm{CF}_{3}\right)$ and the iridium photocatalyst $\quad\left[\operatorname{Ir}\left(\mathrm{dF}\left(\mathrm{CF}_{3}\right) \mathrm{ppy}\right)_{2}(\mathrm{dtbbpy})\right] \mathrm{PF}_{6} \quad(1.0 \quad \mathrm{~mol} \%$, $\mathrm{dF}\left(\mathrm{CF}_{3}\right)$ ppy = 3,5-difluoro-2-(5-trifluoromethyl)-2-pyridine, dtbbpy $=4,4^{\prime}$-di-tert-butyl-2,2'-bipyridine) in MeCN cleanly afforded 1 in $65 \%$ isolated yield (25 mmol scale). ${ }^{[10]}$ The heteroaromatic intermediate was subsequently stirred with MeOTf (3 equiv) in $\mathrm{CH}_{2} \mathrm{Cl}_{2}$ and, after $50 \mathrm{~h}$ at rt, addition of $\mathrm{Et}_{2} \mathrm{O}$ followed by filtration delivered $\mathbf{B T}^{-\mathbf{S C F}_{3}}$ in $\mathbf{9 5 \%}$ yield without the need for further purification.

a)

$$
\text { ( }
$$

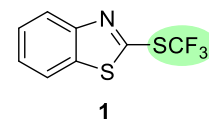

MBTS

$$
1
$$

(65\%, $25 \mathrm{mmol}$ scale)

$$
\begin{array}{c|l}
\text { MeOTf } & \begin{array}{c}
\mathrm{CH}_{2} \mathrm{Cl}_{2} \\
\text { (3 equiv) }
\end{array} \\
\mathrm{rt}, 50 \mathrm{~h}
\end{array}
$$<smiles>[SiH3][SH3+]([S-])CCCCc1ccccc1</smiles>

$3 a$

$$
\mathrm{NEt}_{(i \mathrm{Pr})_{2}(2 \text { equiv })}
$$$$
\mathrm{MeCN}, \mathrm{rt}, 2 \mathrm{~h}
$$

70\%: 2.0 equiv BT-SCF$_{3}, 0.1 \mathrm{M}$ 68\%: 1.1 equiv BT-SCF $_{3}, 0.5 \mathrm{M}$ $85 \%: 1.25$ equiv BT-SCF $_{3}, 0.5 \mathrm{M}$

b)<smiles>C[n+]1c([AsH2])sc2ccccc21</smiles>
$\underset{\mathrm{HO}_{\mathrm{R}}^{\mathrm{NEt}(i \mathrm{Pr})_{2}}}{\longrightarrow}$

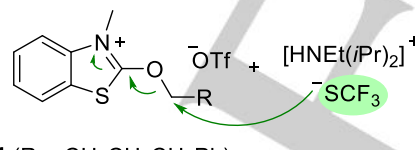<smiles>C[n+]1c(S(F)(F)(F)(F)F)sc2ccccc21</smiles>
BT-SCF 3 $95 \%$<smiles>[194Sb]</smiles>

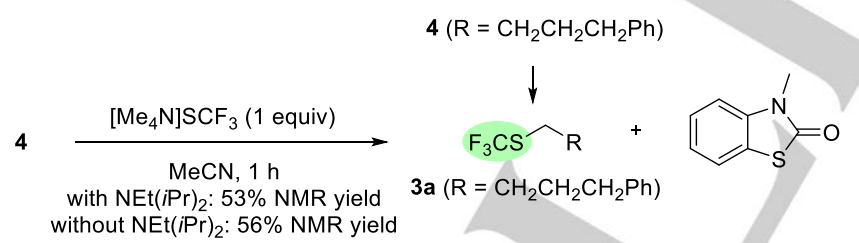

Scheme 2. a) Two-step synthesis of $\mathbf{B T}-\mathbf{S C F}_{3}$ and its application in the deoxytrifluoromethylthiolation of aliphatic alcohol $2 \mathrm{a}$. b) Likely reaction mechanism via 2-alkoxybenzothiazolium salt 4.

BT-SCF 3 is an off-white solid that is stable over at least several months under ambient conditions and hydrolyses only slowly in neutral or acidic $\mathrm{MeCN} / \mathrm{H}_{2} \mathrm{O}$ solutions. ${ }^{[11]}$ In the presence of Hünig's base $\left(\mathrm{NEt}(\mathrm{Pr})_{2}\right)$, however, fast hydrolysis to the corresponding benzothiazolone is observed. This result validates the proposed mode of action of $\mathbf{B T}^{-\mathbf{S C F}_{3}}$ and we accordingly turned our attention to the development of a nucleophilic trifluoromethylthiolation process. Addition of an aliphatic alcohol rather than water, for example, would deliver a 2alkoxybenzothiazolium salt susceptible to subsequent nucleophilic substitution by the released ${ }^{-} \mathrm{SCF}_{3}$ anion. Deoxytrifluoromethylthiolation reactions are synthetically

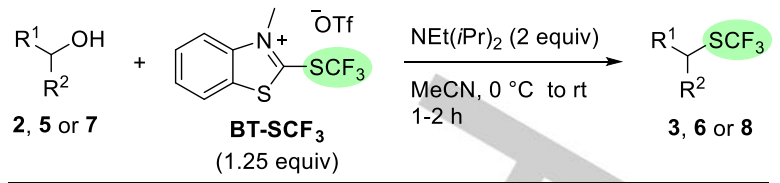

Primary Aliphatic Alcohols 2:

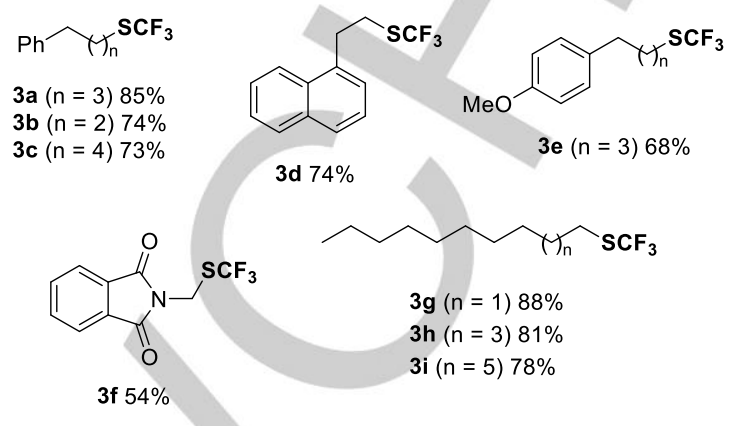

Benzylic (or Propargylic) Alcohols 5

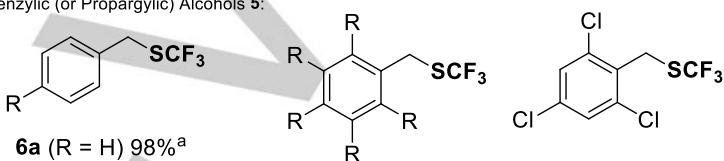

6b $\left(\mathrm{R}=\mathrm{NO}_{2}\right) 87 \%$

6c $\left(\mathrm{R}=\mathrm{CO}_{2} \mathrm{Me}\right) 94 \%$

$\mathrm{R}$

$6 \mathrm{~m} 91 \%$

6d $(\mathrm{R}=\mathrm{Cl}) 98 \%{ }^{\mathrm{a}}$

6 e $(R=B r) 89 \%$

$6 f(R=I) 57 \%$

$6 \mathrm{~g}(\mathrm{R}=\mathrm{SMe}) 90 \%$

6h $(\mathrm{R}=\mathrm{Me}) 74 \%^{\mathrm{a}}$

$6 \mathbf{i}\left(\mathrm{R}=\mathrm{CF}_{3}\right) 84 \%^{\mathrm{a}}$

6k $(\mathrm{R}=\mathrm{Br}) 45 \%$

6j $(R=P h) 75 \%$

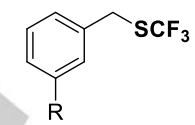

$6 \mathbf{p}\left(\mathrm{R}=\mathrm{NO}_{2}\right) 89 \%$

$6 q(R=B r) 83 \%$

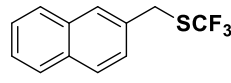

6n $58 \%$<smiles>Fc1ccc(Br)c(CSC(F)(F)F)c1</smiles>

6r $67 \%$<smiles>FC(F)(F)Cc1cccc2ccccc12</smiles>

$6038 \%$<smiles>FC(F)(F)SCc1ccccn1</smiles>

6s $83 \%^{a}$<smiles>FC(F)(F)[Si]CC#Cc1ccccc1</smiles>

6 t $66 \%$
Secondary Alcohols 7

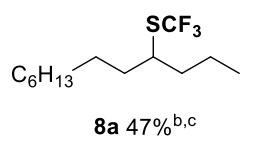<smiles>CC(CCc1ccccc1)C(F)(F)F</smiles><smiles>FC(F)(F)C(c1ccccc1)c1ccccc1</smiles>

8c $55 \%$

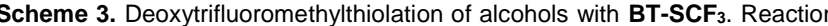
conditions: alcohol $(\mathbf{2}, \mathbf{5}$ or $\mathbf{7}, 0.50 \mathrm{mmol}), \mathbf{B T}_{-} \mathbf{S C F}_{\mathbf{3}}$ (1.25 equiv), NEt(iPr) ${ }_{2}$ (2 equiv), $\mathrm{MeCN}(0.50 \mathrm{M}), 0{ }^{\circ} \mathrm{C}$ to $\mathrm{rt}, 1-2 \mathrm{~h}$. Isolated yields after column chromatography unless otherwise stated. ${ }^{2}{ }^{1} \mathrm{H}$ NMR yield stated due to product volatility (internal standard: $\mathrm{CH}_{2} \mathrm{Br}_{2}$ ). ${ }^{\text {b With }} \mathbf{B T}-\mathbf{S C F}_{3}$ (2 equiv), $-40^{\circ} \mathrm{C}$. ${ }^{\mathrm{c}}$ Isolated as an inseparable mixture with alkene side-products. ${ }^{d}$ With $\mathbf{B T}-\mathbf{S C F}_{3}$ (2 equiv) added portion-wise. ${ }^{e}$ With $\mathbf{B T}^{-S \mathbf{C F}_{3}}$ (3 equiv) added portion-wise, $\mathrm{NEt}(\mathrm{IPr})_{2}(3$ equiv).

attractive as they avoid pre-activation steps and provide valuable

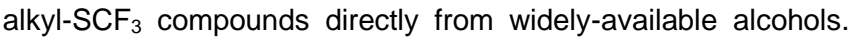
Previously-reported methods by Qing, ${ }^{[12]}$ Billard ${ }^{[13]}$ and Pégot \& Magnier ${ }^{[14]}$ have exploited the aforementioned instability of ${ }^{-} \mathrm{SCF}_{3}$ with substitution occurring on an in situ-generated carbonofluoridothioate intermediate (Scheme 1b). This approach, however, requires excess amounts of the expensive trifluoromethylthiolating reagent and high reaction temperatures. 
Rueping and co-workers reported a room temperature method using only 1.5 equivalents of $\mathrm{CuSCF}_{3}$ and 2 equivalents of the Lewis acid $\mathrm{BF}_{3} \cdot \mathrm{OEt}_{2}$, however, the scope of this process was limited to activated benzylic and allylic alcohols capable of stabilizing the intermediate carbocation. ${ }^{[15,16]}$

In an initial experiment, the primary aliphatic alcohol 2a was reacted with 2 equivalents of both $\mathbf{B T}-\mathbf{S C F}_{3}$ and $\mathrm{NEt}(\mathrm{Pr})_{2}$ in MeCN (0.1 M). After 2 hours at rt, we were delighted to observe clean conversion to the corresponding alkyl-SCF 3 derivative $\mathbf{3 a}$, which could be isolated in $70 \%$ yield after column chromatography. Notably, the reaction proceeded smoothly under ambient conditions and no special precautions to exclude air or moisture were required (Scheme 2a). Optimisation of the reaction conditions confirmed the requirement for a base with $\mathrm{NEt}(\mathrm{Pr})_{2}(2$ equiv) in MeCN providing $3 \mathbf{a}$ in the highest yields. ${ }^{[1]}$ Moreover, upon increasing the concentration to $0.5 \mathrm{M}$, efficient deoxytrifluoromethylthiolation could be achieved using only a

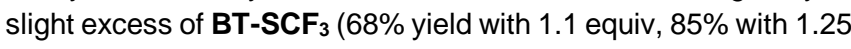
equiv). Aside from the obvious practical advantages, the low reagent loading indicates that carbonofluoridothioate intermediates generated through $\beta$-fluoride elimination of ${ }^{-} \mathrm{SCF}_{3}$ are not the major electrophilic species in this process and that 2alkoxybenzothiazolium intermediates are likely involved (Scheme 2b). ${ }^{[12-14]}$ This mechanism was further validated by the successful formation of 3a upon reacting the independently synthesized 2(4-phenylbutoxy)benzothiazolium salt 4 with $\left[\mathrm{Me}_{4} \mathrm{~N} \mathrm{SCF}_{3}\right.$ (53\% and $56 \%{ }^{1} \mathrm{H}$ NMR yield with or without $\mathrm{NEt}(\mathrm{iPr})_{2}$, respectively).
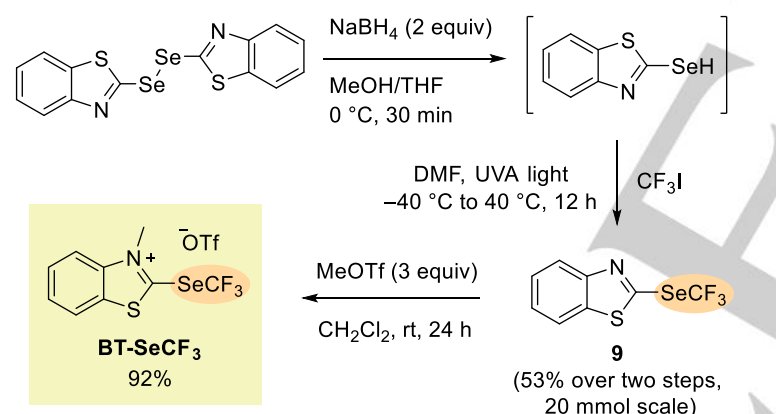
DMF, UVA light
$-40^{\circ} \mathrm{C}$ to $40^{\circ} \mathrm{C}, 12 \mathrm{~h}$

$$
\begin{aligned}
& \text { MeOTf (3 equiv) } \\
& \mathrm{CH}_{2} \mathrm{Cl}_{2}, \mathrm{rt}, 24 \mathrm{~h} \\
& 24 \mathrm{~h}
\end{aligned}
$$

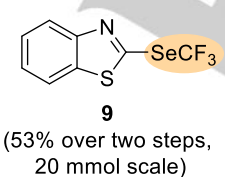

Scheme 4. Synthesis of BT-SeCF 3 .

With a set of optimized conditions in hand, the scope and limitations of the metal-free deoxytrifluoromethylthiolation process with a range of alcohols was evaluated (Scheme 3). Primary aliphatic alcohols 2 reacted smoothly to afford the corresponding trifluoromethylthiolated products $\mathbf{3 a - i}$ in moderate to excellent yields up to $88 \%$. In each case, complete conversion was observed within 2 hours under ambient conditions and the trifluoromethylthiolated products could be easily isolated by column chromatography. A wide range of diversely-substituted benzylic alcohols $\mathbf{5}$ could also be smoothly transformed into the corresponding trifluoromethyl thioethers $6 a-t$ under the same mild conditions. Benzylic alcohols bearing electron-withdrawing groups such as $\mathrm{NO}_{2}$ and $\mathrm{CO}_{2} \mathrm{Me}$ at the para-position were particularly effective substrates, delivering the corresponding $\mathrm{SCF}_{3}$-containing products $6 \mathrm{~b}$ and $6 \mathrm{c}$ in $87 \%$ and $94 \%$ yield, respectively. Comparatively electron-neutral substituents were also successfully deoxytrifluoromethylthiolated, however, strongly electron-donating para-substituents such as OMe led to complex reaction mixtures, presumably due to the instability of the 2alkoxybenzothiazolium intermediates. The halogen-substituents $\mathrm{Cl}, \mathrm{Br}$ and I were all tolerated under the reaction conditions, opening up the possibility of subsequent elaboration of the products through cross-coupling methodologies. Substitution at the meta-position of the aryl rings was well tolerated with the meta- $\mathrm{NO}_{2}$ and meta- $\mathrm{Br}$ derivatives $6 \mathbf{p}$ and $\mathbf{6 q}$ being afforded in $89 \%$ and $83 \%$ yields, respectively. Trifluoromethylthioether $6 r$, which features an ortho- $\mathrm{Br}$ and meta- $\mathrm{F}$ substituent was also isolated in $67 \%$ yield, while the propargyl alcohol 5 t was successfully converted to $\mathrm{SCF}_{3}$-substituted product $6 \mathrm{t}$ in $66 \%$ yield. In addition to primary alcohols, a selection of secondary alcohols 7 could also be deoxytrifluoromethylthiolated using BT$\mathbf{S C F}_{3}$. Two or three equivalents of the reagent were required to effect complete conversion of these more sterically-hindered substrates with the highest yields being obtained upon adding BT$\mathbf{S C F}_{3}$ portion-wise over 2 hours.

The successful synthesis and application of $\mathbf{B T}-\mathbf{S C F}_{3}$ as a new nucleophilic reagent for installing the trifluoromethylthio group onto organic molecules encouraged us to consider whether the same approach could be adapted to prepare $\mathrm{SeCF}_{3-}$ substituted compounds. Selenium derivatives are attracting increasing interest for applications in materials and medicinal chemistry. ${ }^{[17]}$ With a Hansch parameter $(\pi)$ of $1.29^{[18]}$ and Hammett constants $\sigma_{\mathrm{m}}$ and $\sigma_{\mathrm{p}}$ of 0.44 and $0.45,{ }^{[19]}$ respectively, the $\mathrm{SeCF}_{3}$ group has lipophilic and electronic properties between those of $\mathrm{SCF}_{3}$ and $\mathrm{OCF}_{3}$ and could thus allow for better fine tuning of a molecule's properties. Despite notable recent advances, ${ }^{[17,20]}$ the synthesis of $\mathrm{SeCF}_{3}$-substituted compounds remains dominated by indirect methods and, to the best of our knowledge, there is no previous report of a direct deoxytrifluoromethylselenylation reaction of alcohols.
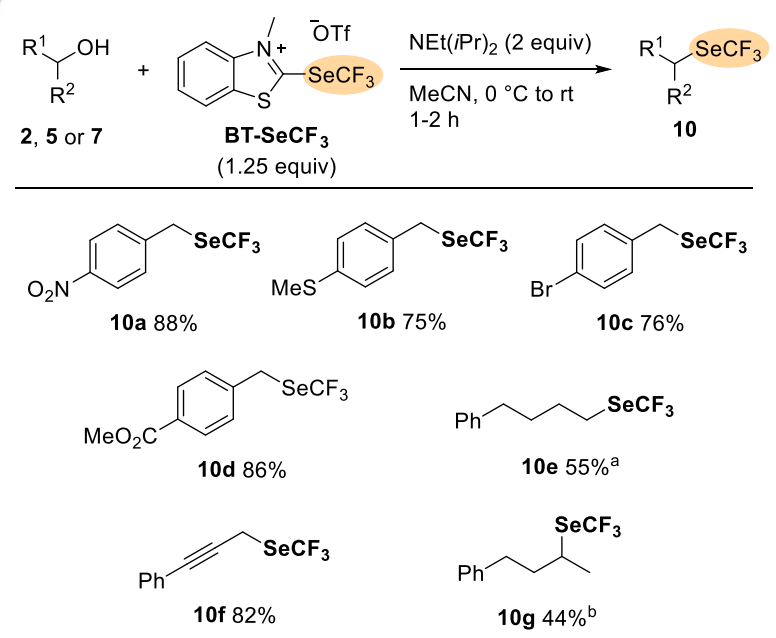

Scheme 5. Deoxytrifluoromethylselenylation of alcohols with BT-SeCF 3 . Reaction conditions: alcohol $(\mathbf{2}, \mathbf{5}$ or $\mathbf{7}, 0.20 \mathrm{mmol}), \mathbf{B T}^{-\mathrm{SeCF}_{3}}$ (1.25 equiv), $\mathrm{NEt}(\operatorname{iPr})_{2}$ (2 equiv), $\mathrm{MeCN}(0.50 \mathrm{M}), 0^{\circ} \mathrm{C}$ to rt, $1-2 \mathrm{~h}$. Isolated yields after column chromatography. ${ }^{a}$ Reaction performed at $-40{ }^{\circ} \mathrm{C}$. ${ }^{\mathrm{b}}$ Reaction performed at $-40{ }^{\circ} \mathrm{C}, \mathrm{BT}^{-\mathrm{SeCF}_{3}}$ (2 equiv). 
BT-SeCF 3 was synthesized via the same general strategy used

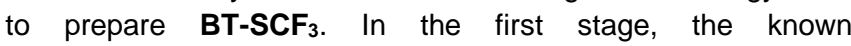
trifluoromethylselenylated benzothiazole $\mathbf{9}^{[21]}$ was prepared in $53 \%$ yield from bis(2-benzothiazolyl)diselenide upon sequential reduction with $\mathrm{NaBH}_{4}$ and UVA light-facilitated radical trifluoromethylation with $\mathrm{CF}_{3} \mathrm{I}$ and $\mathrm{NaH} .{ }^{\left[{ }^{\circ},\right.}{ }^{22]}$ Subsequent methylation with MeOTf ( 3 equiv) in $\mathrm{CH}_{2} \mathrm{Cl}_{2}$ at $\mathrm{rt}$ for $24 \mathrm{~h}$ provided pure $\mathbf{B T}-\mathrm{SeCF}_{3}$ in $92 \%$ yield upon precipitation with $\mathrm{Et}_{2} \mathrm{O}$ and

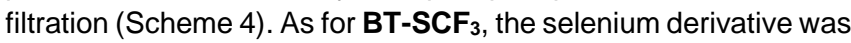
obtained as an off-white solid that is remarkably stable towards

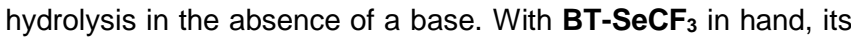
potential as a reagent for deoxytrifluoromethylselenylation reactions was tested with a selection of aliphatic alcohols (Scheme 5). Upon treating the benzylic alcohol $\mathbf{5 b}$ with $\mathbf{B T}_{-} \mathbf{S e C F}_{3}$ (1.25 equiv) under the same mild reaction conditions used with BT-SCF 3 , a clean deoxytrifluoromethylselenylation process was observed leading to the $\mathrm{SeCF}_{3}$-substituted product $10 \mathrm{a}$ in $88 \%$ yield. Moreover, several other benzylic and propargylic alcohols reacted with similarly high yields while, upon decreasing the reaction temperature to $-40{ }^{\circ} \mathrm{C}$, the primary aliphatic alcohol 2a and even the secondary alcohol $7 \mathrm{~b}$ could be successfully transformed into the corresponding selenoethers $10 \mathrm{e}$ and $10 \mathrm{~g}$ in $55 \%$ and $44 \%$ yield, respectively.

In conclusion, we have introduced two new reagents for installing valuable fluorine-containing functional groups onto organic compounds. Based on the benzothiazolium motif, BT$\mathbf{S C F}_{3}$ and $\mathbf{B T}_{-} \mathbf{S e C F}_{3}$ are bench stable and easy to handle solids that release ${ }^{-} \mathrm{SCF}_{3}$ or ${ }^{-} \mathrm{SeCF}_{3}$ anions in a controlled fashion upon

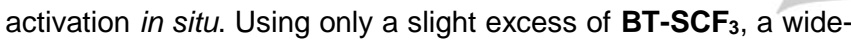
range of aliphatic alcohols can be successfully converted into the corresponding trifluoromethylthioethers at room temperature while $\quad \mathbf{B T}_{-} \mathrm{SeCF}_{3}$ enables hitherto unprecedented deoxytrifluoromethylselenylation reactions. We believe that benzothiazolium salts could open up new routes towards important organofluorine compounds and further studies are underway in our laboratory.

\section{Acknowledgements}

The authors thank Henry Simmons (University of Durham, UK) for initial experiments and helpful discussions. Financial support from the Deutsche Forschungsgemeinschaft (DFG, German Research Foundation) through the Research Training Network "Fluorine as a Key Element" (GRK 1582) and Project Number 387284271 (SFB 1349, "Fluorine-Specific Interactions"), and from the Fonds der chemischen Industrie ( $\mathrm{FCl}$, Sachkostenzuschuss) is gratefully acknowledged.

Keywords: fluorine $\cdot$ reagent development $\cdot$ trifluoromethylthio $\left(\mathrm{SCF}_{3}\right)$ group $\bullet$ trifluoromethylselenyl $\left(\mathrm{SeCF}_{3}\right)$ group $\cdot$ alcohols

[1] Selected Reviews: a) K. Müller, C. Faeh, F. Diederich, Science 2007, 317, 1881-1886; b) S. Purser, P. R. Moore, S. Swallow, V. Gouverneur, Chem. Soc. Rev. 2008, 37, 320-330; c) R. Berger, G. Resnati, P. Metrangolo, E. Weber, J. Hulliger, Chem. Soc. Rev. 2011, 40, 34963508; d) J. Wang, M. Sánchez-Roselló, J. L. Aceña, C. del Pozo, A. E. Sorochinsky, S. Fustero, V. A. Soloshonok, H. Liu, Chem. Rev. 2014 114, 2432-2506; e) T. Fujiwara, D. O'Hagan, J. Fluorine Chem. 2014,
167, 16-29; f) A. Harsanyi, G. Sandford, Green Chem. 2015, 17, 2081 2086

[2] Reviews: a) X.-H. Xu, K. Matsuzaki, N. Shibata, Chem. Rev. 2015, 115 731-764; b) S. Barata-Vallejo, S. Bonesi, A. Postigo, Org. Biomol. Chem. 2016, 14, 7150-7182; c) H. Chachignon, D. Cahard, Chin. J. Chem. 2016, 34, 445-454; d) A.-L. Barthelemy, E. Magnier, G. Dagousset, Synthesis 2018, 50, 4765-4776.

[3] Selected examples: a) S. Munavalli, D. K. Rohrbaugh, D. I. Rossman, F. J. Berg, G. W. Wagner, H. D. Durst, Synth. Commun. 2000, 30, 28472854; b) A. Ferry, T. Billard, B. R. Langlois, E. Bacqué, Angew. Chem. Int. Ed. 2009, 48, 8551-8555; c) T. Bootwicha, X. Liu, R. Pluta, I. Atodiresei, M. Rueping, Angew. Chem. Int. Ed. 2013, 52, 12856-12859; d) X. Shao, X. Wang, T. Yang, L. Lu, Q. Shen, Angew. Chem. Int. Ed. 2013, 52, 3457-3460; e) Y.-D. Yang, A. Azuma, E. Tokunaga, M. Yamasaki, M. Shiro, N. Shibata, J. Am. Chem. Soc. 2013, 135, 87828785; f) S. Alazet, L. Zimmer, T. Billard, Chem. Eur. J. 2014, 20, 8589 8593; g) C. Xu, B. Ma, Q. Shen, Angew. Chem. Int. Ed. 2014, 53, 9316 9320; h) P. Zhang, M. Li, X.-S. Xue, C. Xu, Q. Zhao, Y. Liu, H. Wang, Y. Guo, L. Lu, Q. Shen, J. Org. Chem. 2016, 81, 7486-7509.

[4] a) R. N. Haszeldine, J. M. Kidd, J. Chem. Soc. 1955, 3871; b) T. Scattolin, K. Deckers, F. Schoenebeck, Angew. Chem. Int. Ed. 2017, 56, 221-224; c) T. Scattolin, M. Pu, F. Schoenebeck, Chem. Eur. J. 2018, 24, 567-571.

[5] S.-G. Li, S. Z. Zard, Org. Lett. 2013, 15, 5898-5901.

[6] a) H. Hayashi, H. Sonoda, K. Fukumura, T. Nagata, Chem. Commun. 2002, 1618-1619; b) N. W. Goldberg, X. Shen, J. Li, T. Ritter, Org. Lett. 2016, 18, 6102-6104.

[7] Review: a) T. Mukaiyama, Angew. Chem. Int. Ed. Engl. 1979, 18, 707 721; Selected examples: b) T. Mukaiyama, K. Hojo, Chem. Lett. 1976, 5, 267-270; c) K. Hojo, T. Mukaiyama, Chem. Lett. 1976, 5, 619-622; d) F. Souto-Bachiller, G. S. Bates, S. Masamune, J. Chem. Soc., Chem. Commun. 1976, 719-720; e) T. Mukaiyama, K. Hojo, Chem. Lett. 1976 5, 893-896; f) S. Kobayashi, M. Tsutsui, T. Mukaiyama, Chem. Lett. 1977, 6, 1169-1172; g) F. A. Souto-Bachiller, S. Masamune, Tetrahedron Lett. 1977, 18, 1881-1884; h) O. Mitsunobu, A. Takemasa, R. Endo, Chem. Lett. 1984, 13, 855-858; i) D. Ravi, H. Babu Mereyala, Tetrahedron Lett. 1989, 30, 6089-6090.

[8] a) N. J. W. Straathof, B. J. P. Tegelbeckers, V. Hessel, X. Wang, T. Noël, Chem. Sci. 2014, 5, 4768-4773; b) J. Rong, L. Deng, P. Tan, C. Ni, Y. Gu, J. Hu, Angew. Chem. Int. Ed. 2016, 55, 2743-2747; c) J.-j. Ma, W. b. Yi, G.-p. Lu, C. Cai, Catal. Sci. Technol. 2016, 6, 417-421; d) J. Rong, L. Deng, P. Tan, C. Ni, Y. Gu, J. Hu, Angew. Chem. Int. Ed. 2016, 55, 2743-2747; e) J.-j. Ma, Q.-r. Liu, G.-p. Lu, W.-b. Yi, J. Fluorine Chem. 2017, 193, 113-117. Synthesis of 1 from other benzothiazole derivatives: f) G. Danoun, B. Bayarmagnai, M. F. Gruenberg, L. J. Goossen, Chem. Sci. 2014, 5, 1312-1316; g) S. Alazet, L. Zimmer, T. Billard, J. Fluorine Chem. 2015, 171, 78-81; h) P. Zhang, M. Li, X.-s. Xue, C. Xu, Q. Zhao, Y. Liu, H. Wang, Y. Guo, L. Lu, Q. Shen, J. Org. Chem. 2016, 81, 74867509; i) M. Zhang, Z. Weng Adv. Synth. Catal. 2016, 358, 386-394.

[9] Selected examples of radical trifluoromethylation of disulfides, see: a) C Wakselman, M. Tordeux, J.-L. Clavel, B. Langlois, J. Chem. Soc., Chem Commun. 1991, 993-994. b) C. Pooput, M. Medebielle, W. R. Dolbier Org. Lett. 2004, 6, 301-303; c) C. Pooput, W. R. Dolbier, M. Médebielle, J. Org. Chem. 2006, 71, 3564-3568; d) C. Gadais, N. Saraiva-Rosa, E. Chelain, J. Pytkowicz, T. Brigaud, Eur. J. Org. Chem. 2017, 246-251.

[10] Higher yields of $\mathbf{1}$ were obtained upon reducing the reaction scale.

[11] See the supporting information for more details.

[12] J.-B. Liu, X.-H. Xu, Z.-H. Chen, F.-L. Qing, Angew. Chem. Int. Ed. 2015 $54,897-900$. For the extension of this method to electron-poor vinyl alcohols and phenols, see: Y.-L. Liu, X.-H. Xu, F.-L. Qing, Tetrahedron 2018, 74, 5827-5832.

[13] Q. Glenadel, A. Tlili, T. Billard, Eur. J. Org. Chem. 2016, 1955-1957.

[14] E. Anselmi, C. Simon, J. Marrot, P. Bernardelli, L. Schio, B. Pégot, E. Magnier, Eur. J. Org. Chem. 2017, 6319-6326.

[15] a) P. Nikolaienko, R. Pluta, M. Rueping, Chem. Eur. J. 2014, 20, $9867-$ 9870. For a recent application on $\alpha$-aminoalcohols, see b) J. Maury, G. Force, B. Darses, D. Lebœuf, Adv. Synth. Catal. 2018, 360, 2752-2756. 
[16] For a two-stage deoxytrifluoromethylthiolation process via a phosphite intermediate, see: a) A. A. Kolomeitsev, K. Y. Chabanenko, G.-V. Röschenthaler, Y. L. Yagupolskii, Synthesis 1994, 145. For a multicomponent method involving difluorocarbene, see: b) J.-J. Luo, M Zhang, J.-H. Lin, J.-C. Xiao, J. Org. Chem. 2017, 82, 11206-11211.

[17] Review: a) A. Tlili, E. Ismalaj, Q. Glenadel, C. Ghiazza, T. Billard, Chem. Eur. J. 2018, 24, 3659-3670.

[18] Q. Glenadel, E. Ismalaj, T. Billard, Eur. J. Org. Chem. 2017, 530-533.

[19] C. Hansch, A. Leo, R. W. Taft, Chem. Rev. 1991, 91, 165-195.

[20] Selected recent examples: a) M. Aufiero, T. Sperger, A. S.-K. Tsang, F. Schoenebeck, Angew. Chem. Int. Ed. 2015, 54, 10322-10326; b) Q. Lefebvre, R. Pluta, M. Rueping, Chem. Commun. 2015, 51, 4394-4397; c) Q. Glenadel, E. Ismalaj, T. Billard, J. Org. Chem. 2016, 81, 8268-8275 d) A. B. Dürr, H. C. Fisher, I. Kalvet, K.-N. Truong, F. Schoenebeck, Angew. Chem. Int. Ed. 2017, 56, 13431-13435; e) C. Ghiazza, V. Debrauwer, C. Monnereau, L. Khrouz, M. Médebielle, T. Billard, A. Tlili, Angew. Chem. Int. Ed. 2018, 57, 11781-11785; f) C. Ghiazza, L. Khrouz, C. Monnereau, T. Billard, A. Tlili, Chem. Commun. 2018, 54, 9909-9912.

[21] a) Q. Tian, Z. Weng, Chin. J. Chem. 2016, 34, 505-510; b) T. Dong, J. He, Z.-H. Li, C.-P. Zhang, ACS Sustainable Chem. Eng. 2018, 6, 13271335.

[22] For a similar trifluoromethylation method with aromatic thiols, see: a) A. Harsányi, É. Dorkó, Á. Csapó, T. Bakó, C. Peltz, J. Rábai, J. Fluorine Chem. 2011, 132, 1241-1246. 


\section{Entry for the Table of Contents}

Layout 2:

\section{COMMUNICATION}

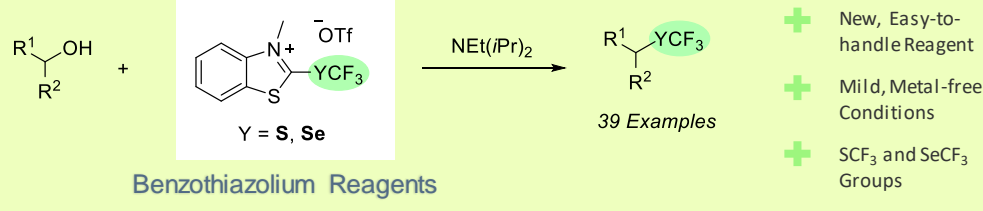

Benzothiazolium salts have been developed as new reagents for installing valuable fluorine-containing functional groups onto organic molecules. The bench stable and easy-to-handle solid $\mathbf{B T}-\mathbf{S C F}_{3}$ delivers a wide range of alkyl-SCF 3 compounds directly from alcohols under mild conditions, while the related selenium derivative $\mathbf{B T}-\mathbf{S e C F}_{3}$ can be employed in unprecedented deoxytrifluoromethylselenylation reactions.
Stefan Dix, Michael Jakob, Matthew N. Hopkinson*

\section{Page No. - Page No.}

Deoxytrifluoromethylthiolation and Selenylation of Alcohols using Benzothiazolium Reagents 